\title{
Utilization of the Teaching Strategies among Nurse Tutors in Malawi Nursing Colleges
}

\author{
Noel D. Mbirimtengerenji ${ }^{1}$, Oluyinka Adejumo² \\ ${ }^{1}$ University of Malawi, Kamuzu College of Nursing, Lilongwe, Malawi \\ ${ }^{2}$ University of Western Cape, Bellville, South Africa \\ Email: ndmbiri@kcn.unima.mw, aodejumo@uwc.ac.za
}

Received 12 March 2015; accepted 26 March 2015; published 30 March 2015

Copyright (C) 2015 by authors and Scientific Research Publishing Inc.

This work is licensed under the Creative Commons Attribution International License (CC BY). http://creativecommons.org/licenses/by/4.0/

(c) (i) Open Access

\begin{abstract}
Background: There are numerous teaching strategies that suit the pedagogical learning, but not all can yield the desired outcome and be properly applied by nurse tutors in both classroom and clinical area. Therefore, identifying the utilization of the teaching strategy for nurse tutors is very detrimental in nursing education. Methods: Descriptive exploratory design which utilized both qualitative and sequential quantitative methods was applied to Iterated Purposive Probability Sampling (IPPS) of 10 nursing colleges in Malawi. This was done to 129 student and 82 nurse tutors in two structured questionnaires, 40 in-depth interviews and 10 focus groups. There were 56 variables for the teaching strategy under five ranked Likert scale and the Cronbach's Alpha was found to be 0.964 without standardisation and it was 0.963 after standardisation. Results: Direct teaching strategies like the lecture method are very common although nurse tutors prefer to combine with other interactive instructions. There is statistical association of use of role play and group discussion methods and nurse tutor work experience with odds ratios of $\mathrm{OR} \leq 1.624$; $\mathrm{CI}(0.576 \pm$ 4.579); $p \geq 0.359$ and $O R \leq 1.397 ; \mathrm{CI}(0.882 \pm 2.306) ; \mathrm{p} \geq 0.147$ respectively. The ability to use different teaching strategies competently is still very limited among nurse tutors in Malawi nursing colleges. This compromises quality of learning among nursing students in the colleges. Conclusion: Developing a new teaching strategy that could combine the different attributes in the variety of the teaching instructions can promote the quality of nursing education in Malawi.
\end{abstract}

\section{Keywords}

Teaching Strategy, Nurse Tutor Experience, Student Study Experience

\section{Introduction}

Nursing is a strong dual professional discipline, what nurse tutors and nursing students do in the classroom area 
is important in readiness for patient care. Teaching activities for nurse tutors provide real life experiences and opportunities for transfer of knowledge to practical situations to students [1].

To justify the enormous activities on classroom and clinical education in nursing, nurse tutors, must have clear, realistic expectations of the desired outcome of both classroom and clinical learning process. This is because, the effectiveness of classroom and clinical teaching should be judged by the extent to which it produces the standardized outcomes. This is only done if nurse tutors follow teaching strategies that are student centered with all the teaching needs available.

There are numerous teaching strategies that suit the pedagogical learning, but not all can yield the desired outcome and be properly applied by nurse tutors in both classroom and clinical area. Nurse tutors interacted teaching strategies are the common teaching strategies that are practiced by nurse tutors in Malawi nursing colleges. But whether these strategies are used properly or not, they have not yet been scientifically classified at length in Malawi nursing colleges. However, the demeaning nursing image and nursing student failure still remain at the news-media front page in the country.

Whether, the low nursing status and student failure is due to limited or poor utilization of the teaching strategies was not yet known. Nurse tutor poor planning, organizing or implementation of their classroom and clinical content so that the students can effectively master the learning process was also not yet document in Malawi literature. It has been pointed out that planning for classroom and clinical teaching by nurse tutors should begin with identifying learning outcomes that are necessary for safe competent nursing practice [2]. Yes, these learning outcomes can be rated very high only if the resources for teaching are adequate for tutors to use.

Teaching is the complex process intended to facilitate learning, while the goal of teaching is to lead students in discovering knowledge for themselves, it is the nurse tutors who encourage this discovery through deliberate teaching actions. However, some actions or behavior of the nurse tutor were much to be desired in most nursing colleges in Malawi.

Literature maintains that poor performance of nursing students is due to an overloaded curriculum [3], however, emphasis being placed on nurse tutor coverage of the content, fragmented and artificial learning process, duplication among disciplines or subjects and the behavioural-objective model with its authoritarian nursing stance was also pinpointed. This results in students demonstrating a lack of retention and integration of knowledge in classroom and the clinical area by the nurse tutor.

Teaching strategies in nursing education are the means or ways that are used to teach nursing care to students. Choice of nursing teaching methods depends on what is needed to teach (content), who are to be taught, and the level of competence expected [4] Content can be divided into the three domains of knowledge: Skills, Attitudes and Values. When teaching knowledge, a variety of methods can be used, with the goal of getting the learner to actively engage in learning the material. When tutors are teaching skills, there is need to demonstrate and point out important aspects, supervise the student doing the skill, or talk to the student through the skill—-"hands on". When teaching about attitudes, [4] there is need to use effective teaching methods to avoid maximum student anxiety that can be the source to gross examination failure. So, whether these processes are done properly or not was yet to be expounded clearly in Malawi nursing colleges. Most nurse tutor like not only resources and skills but also knowledge on current explicit interactive teaching strategies.

Despite nursing education formal training at Kamuzu College of Nursing for tutors to work in the country's nursing colleges, such many nurse training institutions in Malawi cannot achieve the 1:15 tutor-to-student ratio as stipulated by World health Organization [5]. Nurses in Malawi have ratios from 1:20 to 1:50 or more. Even the best ratios raise doubts, however, because they are based on total numbers of staff. The reality is that nurse tutors often have 50 to 200 students in their classes at a time, which creates a burden on tutors to teach effectively or use some student centered teaching strategies. A lot of nurse tutors remain frustrated and make it difficult to be retained in the college for a long time. There was need to establish on how nurse tutors use teaching strategies for all students. In addition to having difficulties achieving the tutor-to-student ratios, there is also a major constraint in all nursing colleges to achieving the recommended nurse instructor/preceptor-to-student ratio of 1:5. Most of the training institutions in Malawi are far from that ratio, ranging from the most optimistic estimate of $1: 27$ to $1: 215$ or more [6].

There is limited evidence in the nursing education literature in Malawi that addresses the transfer of classroom knowledge to the clinical setting where and when active learning and teaching strategies have been used effectively. The absence of these studies provides little incentive for nursing faculties to expand their active learning educational expertise and meet the students' needs. There is also limited evidence where nursing education ad- 
ministrators provide the extra resources needed for active learning and teaching strategies, nor for nursing students to trust that active cooperative learning will lead to success in their clinical performance [7].

There are many new teaching methods or strategies that guide nursing tutors to teach the critical thinking skills necessary for the transfer and use of classroom-acquired knowledge in the clinical setting. Yet many nursing educators in Malawi continue to use teacher-centered educational approaches while identifying an array of barriers for the voiced preference for student-centered education.

In Malawi it is common for nurse tutors and students to feel frustrated, overwhelmed, and academically unprepared for their new roles [8]. This suggest that there are problems with nursing and midwifery education in Malawi.In nursing education, nurse tutors often come from professional background where they have accumulated their knowledge through work experience and skills to become experts in different theoretical and clinical areas. But many nurse tutors have been reported to perform below standard at work resulting in public dissatisfaction and an outcry for better services [9]. Whether such limited understanding is from the amount of classroom content covered, resources available or the type of teaching methods was yet not known or classified in Malawi.

Efforts have been made to intervene in the training colleges through support, and policies from government, but no scientific method or the use of participatory approach have been used to address the problems of nurse tutors on the utilization of the teaching strategies or to bring about solutions to the challenges of the teaching strategies in nursing education in the country.

The type of teaching strategies used in nursing colleges in Malawi currently were questionable as there were strong doubts about effectiveness of the learning environment in facilitating nursing teaching and learning both in class and at the clinical area through college student results.

There is no clear cut understanding or an agreed description of the teaching strategies being currently used in Malawi Nursing Colleges, and the effectiveness of the teaching strategies being used in the Colleges has not been evaluated. Available research, in Malawi, has mainly focused on classroom student assessment but not on the teaching strategies being used by the nurse tutors and their needs at national scale. Although nursing program evaluation was done previously, it only focused on curriculum, resources and student perceptions [9].

It was uncertain what would constitute effective teaching strategies for nursing education in Malawi. There has not been a prior exploration and a purposive design of strategies for teaching and learning in nursing education in Malawi. It will therefore be necessary to explore an effective teaching strategy that will be acceptable for the purpose of producing quality nurses in the country. Therefore, the main objective of this paper was to determine the utilization of the teaching strategies among nurse tutors in Malawi nursing colleges.

Generally, the main teaching strategies have been categorized into five. Direct teaching strategy which is highly teacher-directed is among the most commonly used globably. This strategy is effective for providing information or developing step-by-step skills. It also works well for introducing other teaching methods, or actively involving students in knowledge construction. The main examples include lecture, explicit explanation and didactic teaching. In contrast to the direct instruction strategy, indirect teaching strategy is mainly student-centered, although the two strategies can complement each other. Indirect instruction seeks a high level of student involvement in observing, investigating, drawing inferences from data, or forming hypotheses from concepts [10]. It takes advantage of students' interest and curiosity, often encouraging them to generate alternatives or solve problems. The examples of this strategy include problem solving, case studies and reflective discussion.

However, literature [7] emphasises that interactive teaching strategy relies heavily on discussion and sharing among participants. Nursing students can learn from peers and nurse teachers to develop social skills and abilities, to organize their thoughts, and to develop rational arguments. However, Interactive instruction requires the refinement of observation, listening, interpersonal, and intervention skills and abilities by both teacher and students. The success of the interactive instruction strategies and its many methods is heavily dependent upon the expertise of the nurse tutor in structuring and developing the dynamics of the group.

Furthermore, the third teaching strategy is call experiential learning. Experiential learning is inductive, learner centered, and activity oriented. Personalized reflection about an experience and the formulation of plans to apply learning to other contexts are critical factors in effective experiential learning [7]. The emphasis in experiential learning is on the process of learning and not on the product of learning. The last fifth category of teaching strategy is independent teaching strategy which focuses much on instructional methods which are purposefully provided to foster the development of individual student initiative, self-reliance, and self-improvement. While independent study may be initiated by student or teacher, the focus here is on planned independent study by students under the 
guidance or supervision of a classroom teacher. Such strategies include essay writing, scholarly project learning; report writing and research project [11].

Such various teaching strategies have been used to facilitate learning in the nursing colleges.

Literature has shown that there is increased pressure to be more responsive to nursing students' and tutors needs and more concerned about how well students are prepared through effective teaching strategies for them to assume future societal roles [12]. Tutors are already feeling the pressure to lecture less, to make learning environments more interactive, to integrate technology into the learning experience, and to use collaborative effective learning strategies when appropriate.The use of various teaching strategies should never be underestimated to contribute to the personal development of nursing learners [12].

\section{Methodology}

The study design for this research was descriptive exploratory which utilized both qualitative and sequential quantitative methods. This study was conducted in Malawi from 10 nursing Colleges. The nursing colleges were Ekwendeni and St. Johns Colleges from northern part of Malawi. Malawi college of Health sciences and Nkhoma nursing college were chosen from central region of the country. St Lukes College of Nursing, Trinity College; Malamulo Nursing College, Holy Family Nursing College; Mulanje Nursing College and St Joseph Nursing College were others from southern region. By 2013 there were 158 tutors in all the 10 nursing colleges and 2075 students in these nursing colleges.

Iterated Purposive Probability Sampling (IPPS) was chosen as the recommended sampling frame for nurse tutor and student teaching strategy needs. In order to achieve a sample worthy generalization quantitatively, the sample were obtained from the colleges basing on approximated (random probability) number of tutors and students respectively. Drawing sample from the population was done until the desired sample was achieved and it used the following sample proportion formula:

$$
\text { Sample Size }=n /[1+(n / \text { population })] \text { BUT } \mathbf{n}=Z^{2} P(1-P) / E^{2} \quad \text { (Lemeshow, Hosmer, Klar \& Lwanga, 1990) }
$$

Where $n$ was sample size of tutors and students in colleges, $P$ was the proportion of number of tutors or students and $E$ was the margin error. This formula allowed $05 \%$ for expected margin of error $(E)$ with $95 \%$ confidence level as the denominator. $Z^{2}$ is a constant score with a value of $1.96^{2}$ (at $95 \%$ confidence level and $05 \%$ precision). So, using the same formula of probability sampling described above, it meant that 129 students and 82 nurse tutors iterated randomly selected participated in the study.

Moreover, qualitatively, 42 tutors four from each college, purposively selected, but not among those participating in a questionnaire, participated in qualitative in-depth Interview; while 10 students purposively selected participated in a focus group discussion. This means that using the probability proportional formula above nursing colleges with more nurse tutors had more sample size by calculation.

It has to be added that 10 students in one focus group discussion for each nursing college also participated qualitatively (see Figure 1).

This research involved nurse tutors, nursing students and Deans and Principals who were participating in both classroom and clinical teaching in nursing colleges in Malawi. Only two or more years of work experienced nurse tutors were invited to participate particularly on Focus Group and In-Depth Interview (qualitative data) as a part of the inclusion criteria. Only those tutors that have undergone the teaching methodology training participated in the questionnaire. All tutors who were just recruited and those on transfer and others like foreign expatriates were not included on the basis of lacking contextual experience of teaching strategy needs in Malawi.

There were three main instruments used; structured questionnaire; In-depth interview (IDI) and Focus Group Discussion (FGD). The three instruments thus Questionnaire, In-Depth Interview and Focus group Discussion were administered concurrently to intensify the validity and reduce recall bias. Collected quantitative data were managed by SPSS software version 21.0 and the qualitative data were sorted and stored in ATLAS-ti 7.0.

This research used four criteria for establishing the trust worthiness of qualitative data from the tutors, students and administrators: These are credibility, dependability, confirmability, and transferability. These criteria go beyond an assessment of qualitative data alone, but rather were concerned with evaluations of interpretations and conclusions that was made in the process of classifying the effective teaching strategies that nurse tutors and 


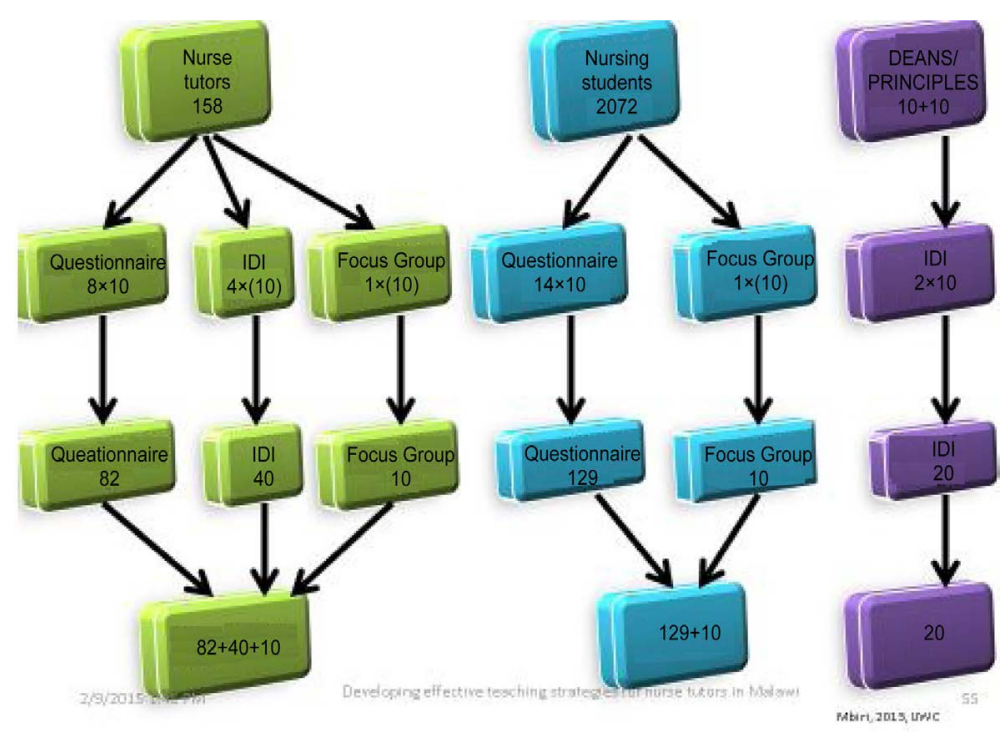

Figure 1. Distribution of sampling and sample size.

students use in both classroom and at the clinical area.

Bias was reduced by doing face to face interview during data collection to iterated randomized nurse tutors and students. Categorizing the participants into three different strata of tutors, student and administrators also helped to reduce bias. Use of limited time on data collection assisted to reduce bias. The inferential analysis of bivariate analysis from spearman correlation coefficient and binary logistic regression adapting the omnibus coefficient model helps to reduce bias and control confounding in the study. The content validity for the instruments of the study was maintained by requesting opinions of the experts from two international universities of which the study was affiliated.

There were five ways on how this study controlled confounding variables. The most important method was randomization, restriction, matching, stratification and inferential analysis. This study had an approval from ethical review boards from, University of Western Cape (UWC) and from University of Malawi (UNIMA) through COMREC. All nursing tutors' and students' participants were assured that no form of human rights violations would be encountered in the due course of the nationwide nursing tutor needs on teaching strategy assessment.

\section{Results}

The results are reflection of analysis for the randomly sampled 129 nursing students and 82 nurse tutors quantitatively with a response rate of $96 \%$ for student and $81 \%$ for the tutors. During analysis the two questionnaires (student and nurse tutor) were classified into seven components that reflected the teaching strategies,

The questionnaires both nurse tutors and student were mostly made of 5 ranked Likert Scale. There were 56 variables for the teaching strategy and the Cronbach's Alpha was found to be 0.964 without standardisation and it was 0.963 after standardisation. This means that the data are very reliable and reflect the real teaching strategies that nurse tutors in Malawi use when teaching in their different colleges.

\section{Distribution of Tutors and Students on the Use of the Teaching Strategies}

In Table 1, using Likert scale only two teaching methods under direct instruction teaching strategy group, were found to be commonly used by tutors. $44.6 \%(55) n=129$ of the students agreed that tutors use lecture teaching method. But $41.1 \%$ (53)n = 129 of the students strongly agree that their tutor has used demonstration strategy during teaching in their class and at the clinical area (see Table 1).

In the interactive instruction category, four teaching strategies were found to be at least used during teaching but not often by nurse tutors in the last semester. 41.9\% (54)n $=129$ of the students agreed that during the last semester they had seen their tutors using role play as a teaching strategy. Furthermore, 49.6\% (64)n = 129 of 
Table 1. Distribution of students on Tutors’ use of teaching strategies $n=129$.

\begin{tabular}{|c|c|c|c|c|c|}
\hline Teaching Strategy & Strongly Disagree & Disagree & Not Sure & Agree & Strongly Agree \\
\hline Direct Instructions: & $\mathrm{N}(\%)$ & $\mathrm{N}(\%)$ & $N(\%)$ & $N(\%)$ & $N(\%)$ \\
\hline Lecture & $5(3.9)$ & $4(3.1)$ & $7(5.4)$ & $55(42.6)$ & $58(45.0)$ \\
\hline Explicit Teaching & $11(8.5)$ & $10(7.8)$ & $44(34.1)$ & 45(34.9) & 19(14.7) \\
\hline Demonstrations & $6(4.7)$ & $7(5.4)$ & $11(8.5)$ & $52(40.3)$ & $53(41.1)$ \\
\hline $\begin{array}{c}\text { Guided \& Shared_-Reading, } \\
\text { Listening, }\end{array}$ & $5(3.9)$ & $6(4.7)$ & 19(14.7) & 67(51.9) & $32(24.8)$ \\
\hline \multicolumn{6}{|l|}{ Interactive Instructions: } \\
\hline Debates & $30(23.3)$ & $30(23.3)$ & 15(11.6) & $42(32.6)$ & $12(9.3)$ \\
\hline Role Playing & $26(20.2)$ & $26(20.2)$ & $10(7.8)$ & $54(41.9)$ & 13(10.1) \\
\hline Brainstorming & $6(4.7)$ & $4(3.1)$ & 14(10.9) & $64(49.6)$ & 41(31.8) \\
\hline Discussion & $3(2.9)$ & $5(3.9)$ & $8(6.2)$ & 43(33.3) & $70(54.3)$ \\
\hline Jigsaw & 25(19.4) & 18(14.0) & $60(46.5)$ & 19(14.7) & $7((5.4)$ \\
\hline \multicolumn{6}{|l|}{ Indirect Instructions: } \\
\hline Problem Solving & $9(7.0)$ & $9(7.0)$ & 21(16.3) & $63(48.8)$ & $26(20.2)$ \\
\hline Case Studies & $4(3.1)$ & $5(3.9)$ & $7(5.4)$ & $58(45.0)$ & $54(41.9)$ \\
\hline Concept Mapping & 14(10.9) & 21(16.3) & 65(50.4) & $18(14.0)$ & $11(8.5)$ \\
\hline \multicolumn{6}{|l|}{ Independent Studies } \\
\hline Essays & $9(7.0)$ & 14(10.9) & 14(10.9) & $42(32.6)$ & $50(38.8)$ \\
\hline Reports & $9(7.0)$ & $11(8.5)$ & $29(22.5)$ & $53(41.1)$ & $27(20.9)$ \\
\hline Learning Activity Packages & $13(10.1)$ & $18(14.0)$ & $44(34.1)$ & $35(27.1)$ & 19(14.7) \\
\hline Homework & $7(5.4)$ & $10(7.8)$ & $16(12.4)$ & $52(40.3)$ & $44(34.1)$ \\
\hline Research Projects & $16(12.4)$ & $10(7.8)$ & 27(20.9) & $37(28.7)$ & $39(30.2)$ \\
\hline \multicolumn{6}{|l|}{ Experiential Learnings: } \\
\hline Field Trips & $36(27.9)$ & 23(17.8) & 20(15.5) & 20(15.5) & $29(22.5)$ \\
\hline Simulations & $26(20.2)$ & 24(18.6) & $52(40.3)$ & 14(10.9) & $11(8.5)$ \\
\hline Storytelling & 24(18.6) & 25(19.5) & $26(20.2)$ & $41(31.8)$ & $11(8.5)$ \\
\hline Clinical Observations & $18(14.0)$ & $30(23.3)$ & 24(18.6) & $34(26.4)$ & 23(17.8) \\
\hline Role-Playing & 23(17.8) & 23(17.8) & 25(19.5) & $36(27.9)$ & $22(17.1)$ \\
\hline Surveys & 24(18.6) & $26(20.2)$ & $35(27.1)$ & $24(18.6)$ & $20(15.5)$ \\
\hline \multicolumn{6}{|l|}{ Instructional Skills: } \\
\hline Explaining & $4(3.1)$ & $1(0.8)$ & $7(5.4)$ & $60(46.5)$ & $57(44.2)$ \\
\hline Demonstrating & $3(2.3)$ & $4(3.1)$ & $5(3.9)$ & $55(42.6)$ & $62(48.1)$ \\
\hline Questioning & $3(2.3)$ & $3(2.3)$ & $1(0.8)$ & 63(48.8) & $59(45.7)$ \\
\hline Questioning Technique & $1(0.8)$ & $9(7.0)$ & $12(9.3)$ & $62(48.1)$ & 45(34.9) \\
\hline
\end{tabular}

students indicated that they had seen some of their tutors using brainstorming as a teaching method in class. But it must also be noted that $46.5 \%(60) n=129$ of the students agreed that they were not sure that they had seen their tutors using Jigsaw as a teaching strategy. This suggests that most of the tutors in Malawi nursing colleges do not use Jigsaw as a teaching strategy both in class and at the clinical area.

However, $54.3 \%(70) \mathrm{N}=129$ of the students agreed that they had seen their nurse tutor using discussion as a teaching strategy in their class. Although 2.9\% (3)n = 129 indicated that they disagreed that they had seen their tutors using the discussion as a teaching strategy, but it must be pointed out that discussion is the common teaching strategy under many interactive instructions for nurse tutors in Malawi.

Although there are more than ten indirect teaching instructions, but nurse tutors in Malawi commonly use problem solving; case study; reflective discussion and concept mapping teaching strategies. It was noticed that $48.8 \%$ (63)n $=129$ of students agreed that the nurse tutors had used problem solving teaching strategy both in class and at the clinical area in the last semester. It has also to be noted that this type of discussion is different from interactive discussion as this discussion focus on student centred approach where the nurse tutor just give 
some class work for the nursing students to discuss on their own.

However, when the students were asked about use of case study as a teaching strategy, $45.0 \%(58) \mathrm{n}=129$ of the students agreed that they had seen tutors using case study while $45.7(59) \mathrm{n}=129$ agreed that they had seen their tutor utilizing reflective discussion during teaching. Although concept mapping is advocated by nurses council, but $50.4 \%(65) \mathrm{n}=129$ of the students indicated that they are not sure that nurse tutors utilise this teaching instruction. It was also noticed that $50.4 \%(65) \mathrm{n}=129$ of the nursing students agreed that their tutor had used concept mapping during the last semester.

On the independent instructions, only three teaching strategies such as essays and clinical reports were found to be ever used by tutors. 38.8\% (50)n $=129$ of the nursing students strongly agreed that their nurse tutors ever used essay questions when they were writing examinations in class. While $41.1 \%$ (53)n $=129$ of students agreed that they had seen their tutors using reports as the teaching strategy. Only 40.3(50)n = 129 of the students agreed that their tutor had ever used home work as a teaching strategy.

In the category of experimental learning, field trip, simulation, story-telling and role play were mostly used by nurse tutors. For example, it was noted that $15.5 \%(20) n=129$ of student had seen their tutors utilizing field or clinical trip as a teaching strategy although $27.9 \%$ (36)n $=129$ of students strongly disagreed that their tutors had used the teaching strategy during the previous semester. However, $27.9 \%$ (36)n $=129$ of the students agreed that they had seen their tutor facilitating a role play as a teaching strategy in their class but not at the clinical area and 19.5(25)n $=129$ of the students were not sure that their tutors had used role play as a teaching strategy in the clinical area. This suggest that role play is not commonly used by nurse tutors as a teaching strategy in the clinical area. When some tutors were asked during in-depth interview they indicated that some of these teaching strategies are new to them and were not oriented on how to use them.

In the category of instructional skills, only demonstration appeared to be highly used by nurse tutors in Malawi. This is because $48.1 \%(62) n=129$ of the students strongly agreed that their tutors had used demonstration method during teaching in the last semester both in class and the clinical area. It was only $2.3 \%$ (3)n $=129$ of the students who strongly disagreed that their tutors has used demonstration as a teaching strategy in class and at the clinical area.

Furthermore, $44.2 \%(57) n=129$ of the students strongly agreed that their tutors had used the explanation strategy when teaching in class and at the clinical area. It was only 3.1\% (4)n $=129$ of the students who strongly disagreed that their tutors used the explanation as a teaching strategy in class. This suggests that instructional skills are commonly used by nurse tutors in all colleges of nursing in Malawi.

In Figure 2, the use of role play as a teaching method was compared in all eight nursing colleges and it was found out that $29 \%$ of the students who strongly disagree with the use of Role play were from Holy Family Nursing College, seconded by students from St. Johns. So, it is still suggesting that use of role play as a teaching strategy is very limited in all nursing colleges in Malawi.

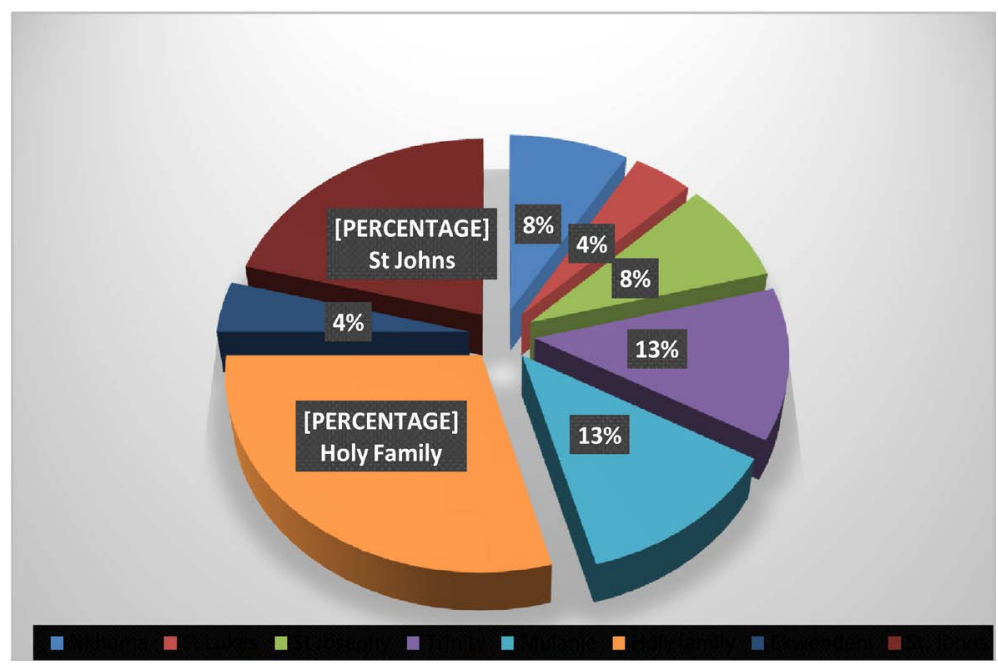

Figure 2. Distribution of tutors who strongly disagree on previous use of rolepaly as a teaching strategy. 
In Table 2 under direct instruction, nurse tutors in different colleges showed that they commonly use lecture method, deductive questioning and demonstrations. 56.1\% (46)n = 82 of the tutors in all colleges strongly agreed that they commonly use lecture teaching strategy. Only $4.9 \%(4) \mathrm{n}=82$ strongly disagreed that they commonly use lecturer method when teaching. Only $28 \%(23) n=82$ of the nurse tutors they strongly agreed that they use also didactic questioning in combination with lecturer method in class and at the clinical area. It has also to be pointed out that $69.5 \%(57) n=82$ of the nurse tutors strongly agreed that they use demonstration both in class and at the clinical area. This is in agreement with the nursing student who also highly agreed that the demonstration is the common teaching strategy both in class and at the clinical area.

Table 2. Distribution of tutors utilization on teaching strategies $\mathrm{N}=82$.

\begin{tabular}{|c|c|c|c|c|c|}
\hline Teaching Strategy & Strongly Disagree & Disagree & Not Sure & Agree & Strongly Agree \\
\hline \multicolumn{6}{|l|}{ Direct Instructions : } \\
\hline Structured Overview & $20(24.4)$ & $6(7.3)$ & $20(24.4)$ & $21(25.6)$ & 15(18.3) \\
\hline Lecture & $4(4.9)$ & $7(8.5)$ & $5(6.1)$ & $20(24.4)$ & $46(56.1)$ \\
\hline Explicit Teaching & 13(15.9) & $11(13.4)$ & $36(43.9)$ & 13(15.9) & $9(11.0)$ \\
\hline Drill \& Practice & $17(20.7)$ & $12(14.6)$ & 15(18.3) & $21(25.6)$ & $17(20.7)$ \\
\hline Compare \& Contrast & 13(15.9) & $11(13.4)$ & $12(14.6)$ & $34(41.5)$ & 12(14.6) \\
\hline Didactic Questions & 15(18.3) & $10(12.2)$ & $21(25.6)$ & $23(28.0)$ & 13(15.9) \\
\hline Demonstrations & $4(4.9)$ & $3(3.7)$ & $1(1.2)$ & $17(20.7)$ & $57(69.5)$ \\
\hline \multicolumn{6}{|l|}{ Interactive Instructions: } \\
\hline Debates & 19(23.2) & $21(25.6)$ & $10(12.2)$ & $20(24.4)$ & 12(14.6) \\
\hline Role Playing & $7(8.5)$ & $11(13.4)$ & $11(13.4)$ & 29(35.4) & $24(29.3)$ \\
\hline Brainstorming & $4(4.9)$ & $11(13.4)$ & $6(7.3)$ & 27(32.9) & $34(41.5)$ \\
\hline Discussion & $1(1.2)$ & $2(2.4)$ & $2(2.4)$ & 27(32.9) & $50(61.0)$ \\
\hline Jigsaw & $28(34.1)$ & $14(17.1)$ & $26(31.7)$ & $10(12.2)$ & $4(4.9)$ \\
\hline Problem Solving & $10(12.2)$ & $10(12.2)$ & $14(17.1)$ & 32(39.0) & 16(19.5) \\
\hline \multicolumn{6}{|l|}{ Indirect Instructions: } \\
\hline Problem Solving & $9(11.0)$ & $5(6.1)$ & $8(9.8)$ & $32(39.0)$ & 28(34.1) \\
\hline Case Studies & $3(3.7)$ & $1(1.2)$ & $5(6.1)$ & 25(30.5) & $48(58.5)$ \\
\hline Reflective Discussion & $7(8.5)$ & $4(4.9)$ & $6(7.3)$ & $40(48.8)$ & $25(30.5)$ \\
\hline Concept Mapping & $20(24.4)$ & $16(19.5)$ & $19(23.2)$ & $21(25.6)$ & $6(7.3)$ \\
\hline \multicolumn{6}{|l|}{ Independent Studies } \\
\hline Essays & 12(14.6) & $8(9.8)$ & $6(7.3)$ & $31(37.8)$ & $25(30.5)$ \\
\hline Journals & $21(25.6)$ & $19(23.2)$ & $17(20.7)$ & $19(23.2)$ & $4(4.9)$ \\
\hline Reports & 13(15.9) & $5(6.1)$ & $5(6.1)$ & $38(46.3)$ & $21(25.6)$ \\
\hline Homework & $7(8.5)$ & $6(7.3)$ & $2(2.4)$ & $36(43.9)$ & $31(37.8)$ \\
\hline Research Projects & $24(29.3)$ & $10(12.2)$ & $13(15.9)$ & $22(26.8)$ & $13(15.9)$ \\
\hline \multicolumn{6}{|l|}{ Experiential Learnings: } \\
\hline Field Trips & $23(28.0)$ & $11(13.4)$ & $9(11.0)$ & $16(19.5)$ & $23(28.0)$ \\
\hline Narratives & 21(23.6) & 16(19.6) & 13(15.9) & $24(29.3)$ & $8(9.8)$ \\
\hline Simulations & $9(11.0)$ & $12(14.6)$ & $10(12.2)$ & $27(32.9)$ & $24(29.3)$ \\
\hline Storytelling & $22(26.8)$ & $19(23.2)$ & $9(11.0)$ & $19(23.2)$ & 13(15.9) \\
\hline Clinical Observations & $10(12.2)$ & $11(13.4)$ & $9(11.0)$ & $28(34.1)$ & $24(29.3)$ \\
\hline Role-Playing & $10(12.2)$ & $12(14.6)$ & $8(9.8)$ & 27(32.9) & $25(30.5)$ \\
\hline Model Building & 21(23.6) & $23(28.0)$ & 13(15.9) & $15(18.3)$ & $10(12.2)$ \\
\hline Surveys & $22(26.8)$ & $22(26.8)$ & $10(12.2)$ & $14(17.1)$ & $14(17.1)$ \\
\hline \multicolumn{6}{|l|}{ Instructional Skills: } \\
\hline Explaining & $2(2.4)$ & $1(1.2)$ & $3(3.7)$ & $25(30.5)$ & $51(62.2)$ \\
\hline Demonstrating & $1(1.2)$ & $4(4.9)$ & $4(4.9)$ & 21(23.6) & $52(63.4)$ \\
\hline Questioning & $1(1.2)$ & $3(3.7)$ & $1(1.2)$ & $30(36.5)$ & $47(57.3)$ \\
\hline
\end{tabular}

This is a descriptive table with frequencies from a Likert scaled categorised for teaching strategies. 
On the interactive teaching instructions, nurse tutors were found to be using mainly role play, brainstorming, discussion, problem solving and tutorial groups. $35.4 \%(29) n=82$ of the nurse tutors agreed that they used role playing as teaching strategy both in class and at the clinical area. However, only $8.5 \%(7) n=82$ of the nurse tutors disagreed to have used the role play as teaching strategy during the last semester. This is in contrast with the nursing students who mainly disagreed that tutors use role play most often as a teaching strategy in class. $41.5 \%$ $(34) n=82$ of the nurse tutors strongly agreed that they have used brainstorming as an interactive teaching instruction during the last semester both in class and at the clinical area. $61.0 \%(50) n=82$ of the nurse tutors strongly agreed that they had used discussion as a teaching instruction during the last semester both in class and at the clinical area.

On the indirect teaching instructions nurse tutors, have been commonly using problem solving, reflective discussion and concept mapping. 39.0\% (32)n $=82$ of the nurse tutors agreed that they have been using problem solving as a teaching strategy both in class and at the clinical area. However, only $6.1 \%(5) n=82$ of the nurse tutors disagreed that they had used problem solving during the last semester when teaching both in class and the clinical area. $48.8 \%(40) n=82$ of the nurse tutors agreed that they have used reflective discussion as a teaching strategy both in class and the clinical area. Although problem solving and reflective discussion teaching strategies are commonly used by nurse tutors as indirect teaching instructions only 7.3\% (6)n $=82$ of the nurse tutors strongly agreed that they have used concept mapping during teaching in the last semester.

In Figure 3, nurse tutors use of direct teaching instructions was tabulated on a grid box plot. It was clearly observed that nurse tutors disagree to use of guided read and listen, lecturer, demonstration and explicit teaching. But they agreed to use of deductive questioning, drill and practice, compare and contrast and structured overview. This suggest that although there are many types of indirect instructions, nurse tutors in Malawi only use limited teaching strategies and in a mixed format rather than a stand-alone strategy.

On Independent studies, nurse tutors indicated that they commonly use essays, reports and homework. 30.5\% (25)n $=82$ of the nurse tutors agreed that they have used essay writing as a method of teaching during the last semester. Only $9.8 \%(8)$ or the nurse tutors disagreed that they have provided essays to their students as a type of teaching during the last semester. It has also to be noted that $46.3 \%(38) n=82$ of the nurse tutors agreed that they have used report writing during as a teaching strategy both in class and the clinical area. In addition, 43.9\% (36)n $=82$ of the nurse tutors agreed that they have used homework when teaching as a strategy both in class and at the clinical area. But only 8.5\% (7)n $=82$ of the nurse tutors strongly disagreed that they have used the

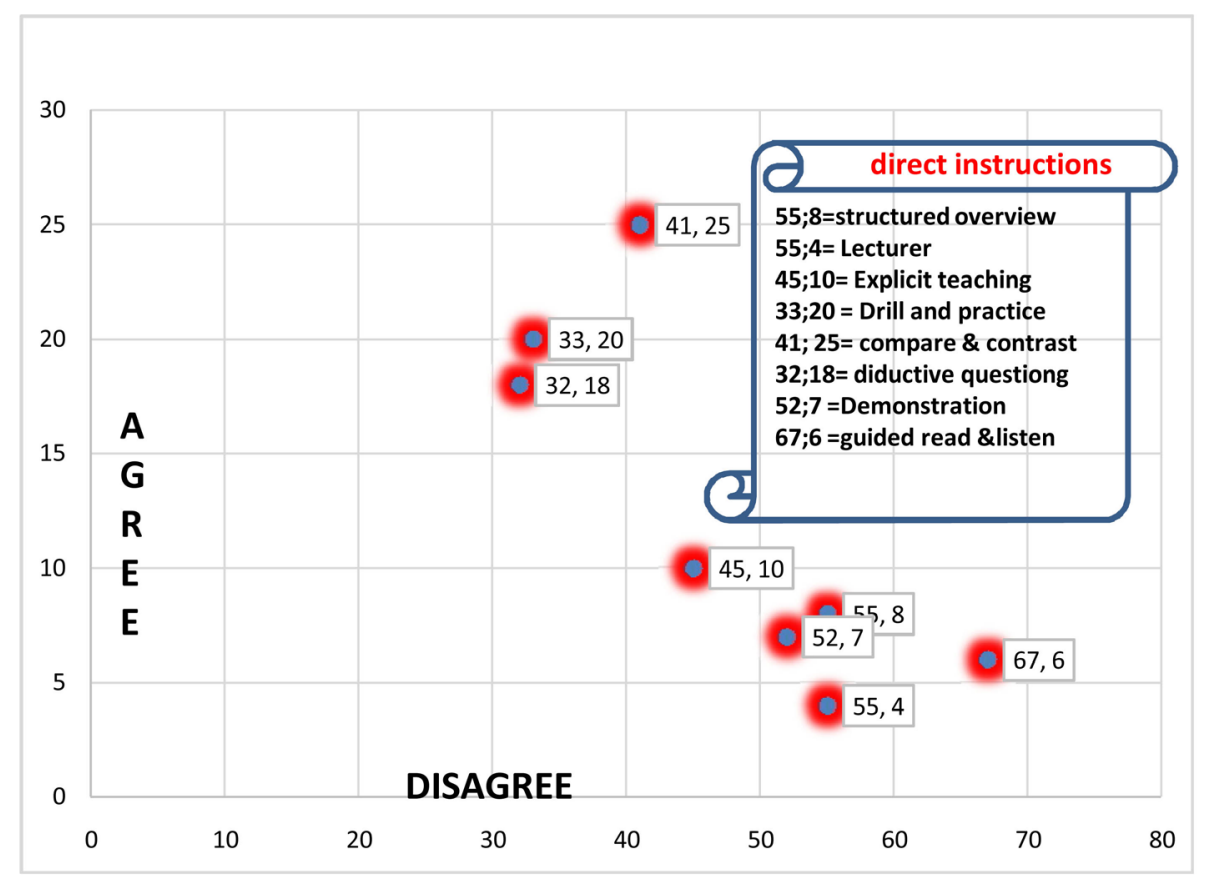

Figure 3. Distribution of tutors on the use of direct teaching instructions on whether they agree or disagree. 
homework as a teaching strategy both in class and at the clinical area.

On the experiential teaching instructions field trip, simulation and Clinical observation were commonly used teaching strategies. It was noted that $28.0 \%(23) n=82$ of the nurse tutors agreed that they have used field trip as a teaching strategy both in class and at the clinical area. However, another $28.0 \%(23) n=82$ of the nurse tutors strongly disagreed that they have used field trip as a teaching strategy during the last semester. $32.9 \%$ (24)n $=82$ of the nurse tutors agreed that they have used simulation as a teaching strategy both in class and the clinical area during the last semester. But $11.0 \%(9) n=82$ of the nurse tutors strongly disagreed that they have used simulation as a teaching strategy during the last semester. $29.3 \%(24) \mathrm{n}=82$ of the nurse tutors strongly agreed that they have used clinical observation as a teaching strategy particularly at the clinical area. But $12.2 \%$ $(10) n=82$ of the nurses strongly disagreed that they have used clinical observation as a teaching strategy during last semester.

In Figure 4, the use of lecture teaching strategy was compared to gender of students and type of the nursing college in a box plot. It was noted that in almost all colleges students agreed that their nurse tutors use the lecture teaching strategy and the female nurse tutors commonly use the strategy than male tutors. However, there was no difference in utilization of the teaching strategy in St. Johns, St. Lukes and Holy family on the gender of the nurse tutors and use of the teaching strategy as showing in the diagram above.

In Figure 5, when the utilisation of brainstorming teaching strategy was compared in different nursing colleges for nurse tutors, it was noted that $17.0 \%(22) \mathrm{n}=82$ of the nurse tutors who strongly disagreed on the use of brainstorming were from St. Lukes Nursing Colleges. While Holy Family Nursing College, Mulanje Nursing College and Nkhoma Nursing College, 15.0\% (20)n = 82 had disagreed on the use of brainstorming as a teaching strategy during the last semester.

\section{Distribution of Student Study Experience and Tutors Work Experience}

Table 3 shows the distribution of the students study experience and nurse tutors work experience in relation to the dependent variables of teaching strategies. Use of interview and use of field trip when teaching and learning has been found to have strong correlation with tutors work experience and students study experience. There is also mixed reactions among tutors and nursing students on the use of lecture, discussion and case study teaching strategies.

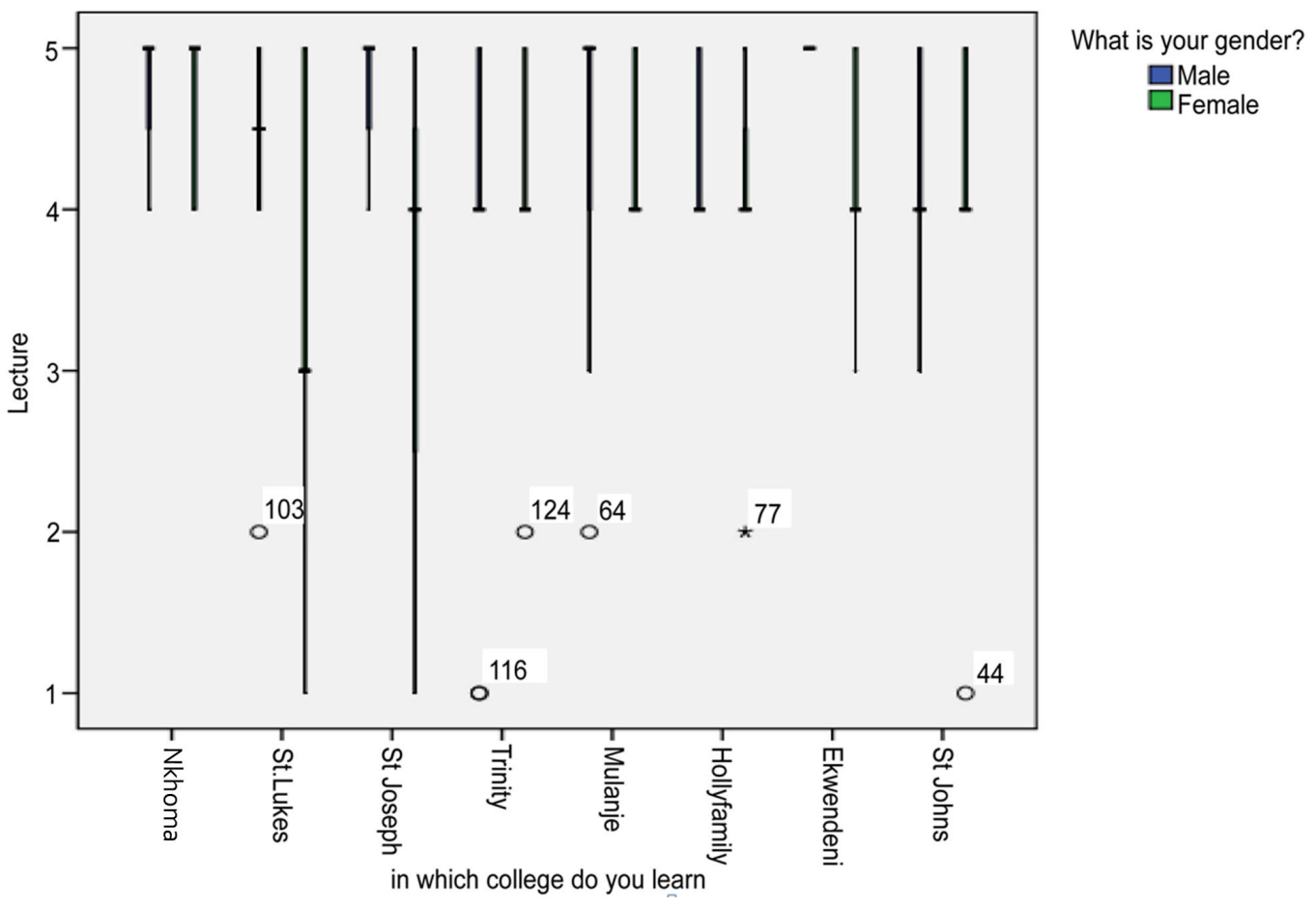

Figure 4. Relationship of gender, type of college and lecture teaching strategy. 


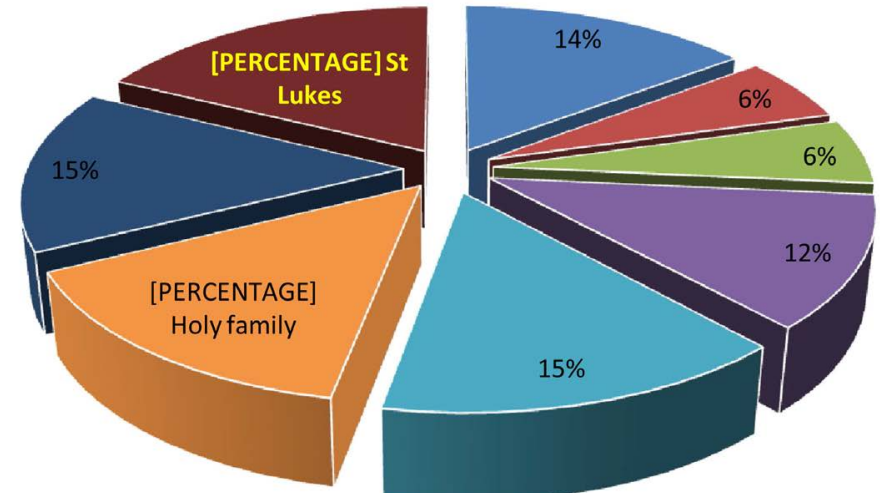

- Nkhoma $\|$ St Lukes $\|$ St Josephy $\|$ Trinity $\approx$ Mulanje $=$ Holy family $\|$ Ekwendeni $\|$ St. Johns

Figure 5. Distribution of tutors who strongly disagree on the use of brainstorming as a teaching strategy.

Table 3. Distribution of tutors' work experience \& students'study experience on use of teaching strategy.

\begin{tabular}{|c|c|c|c|c|c|c|c|c|c|c|c|c|}
\hline \multirow{3}{*}{\begin{tabular}{|c|}
$\begin{array}{c}\text { Teaching strategy } \\
\text { variable }\end{array}$ \\
Use of lecture method
\end{tabular}} & \multicolumn{4}{|c|}{$\begin{array}{c}\text { Tutors work } \\
\text { experience } \mathrm{N}=82\end{array}$} & \multirow{3}{*}{\begin{tabular}{|l} 
Total \\
$\mathbf{n}(\%)$ \\
\end{tabular}} & \multirow[t]{3}{*}{ p-value } & \multicolumn{4}{|c|}{$\begin{array}{l}\text { Students study experience } \\
\qquad \mathrm{N}=129\end{array}$} & \multirow{3}{*}{\begin{tabular}{|l} 
Total \\
N(\%)
\end{tabular}} & \multirow{3}{*}{$\begin{array}{l}\text { p-value } \\
\text {-value }\end{array}$} \\
\hline & \multicolumn{2}{|c|}{1 - 5 years } & \multicolumn{2}{|c|}{6 and more yrs } & & & \multicolumn{2}{|c|}{ Two year } & \multicolumn{2}{|c|}{ More than two yrs } & & \\
\hline & $\mathbf{n}$ & $\%$ & $\mathbf{n}$ & $\%$ & & & $\mathbf{n}$ & $\%$ & $\mathbf{n}$ & $\%$ & & \\
\hline Strongly disagree & 0 & $0.0 \%$ & 4 & $100.0 \%$ & $4(100)$ & \multirow{5}{*}{0.009} & 1 & $20.0 \%$ & 4 & $80.0 \%$ & 5 & \multirow{5}{*}{0.335} \\
\hline Disagree & 5 & $71.4 \%$ & 2 & $28.6 \%$ & $7(100)$ & & 2 & $50.0 \%$ & 2 & $50.0 \%$ & 4 & \\
\hline Not sure & 6 & $30.0 \%$ & 14 & $70.0 \%$ & $20(100)$ & & 4 & $57.1 \%$ & 3 & $42.9 \%$ & 7 & \\
\hline agree & 6 & $30.0 \%$ & 14 & $70.0 \%$ & $20(100)$ & & 26 & $47.3 \%$ & 29 & $52.7 \%$ & 55 & \\
\hline Strongly agree & 21 & $39.0 \%$ & 25 & $61.0 \%$ & $46(100)$ & & 21 & $36.2 \%$ & 37 & $63.8 \%$ & 58 & \\
\hline \multicolumn{13}{|l|}{ Use of discussion } \\
\hline Strongly disagree & 0 & $0.0 \%$ & 1 & $100.0 \%$ & $1(100)$ & \multirow{5}{*}{0.033} & 1 & $33.3 \%$ & 2 & $66.7 \%$ & 3 & \multirow{5}{*}{0.396} \\
\hline Disagree & 0 & $0.0 \%$ & 2 & $100.0 \%$ & $2(100)$ & & 2 & $40.0 \%$ & 3 & $60.0 \%$ & 5 & \\
\hline Not sure & 2 & $100.0 \%$ & 0 & $0.0 \%$ & $2(100)$ & & 5 & $62.5 \%$ & 3 & $37.5 \%$ & 8 & \\
\hline agree & 13 & $48.1 \%$ & 14 & $51.9 \%$ & $27(100)$ & & 19 & $44.2 \%$ & 24 & $55.8 \%$ & 43 & \\
\hline Strongly agree & 17 & $34.0 \%$ & 33 & $66.0 \%$ & $50(100)$ & & 27 & $38.6 \%$ & 43 & $61.4 \%$ & 70 & \\
\hline \multicolumn{13}{|l|}{ Use of interview teaching } \\
\hline Strongly disagree & 7 & $36.8 \%$ & 12 & $63.2 \%$ & $19(100)$ & \multirow{5}{*}{$0.032^{*}$} & 10 & $37.0 \%$ & 17 & $63.0 \%$ & 27 & \multirow{5}{*}{$0.035^{*}$} \\
\hline Disagree & 7 & $41.2 \%$ & 10 & $58.8 \%$ & $17(100)$ & & 6 & $21.4 \%$ & 22 & $78.6 \%$ & 28 & \\
\hline Not sure & 4 & $36.4 \%$ & 7 & $63.6 \%$ & $11(100)$ & & 14 & $48.3 \%$ & 15 & $51.7 \%$ & 29 & \\
\hline agree & 9 & $39.1 \%$ & 14 & $60.9 \%$ & $23(100)$ & & 18 & $52.9 \%$ & 16 & $47.1 \%$ & 34 & \\
\hline Strongly agree & 5 & $41.7 \%$ & 7 & $58.3 \%$ & $12(100)$ & & 6 & $54.5 \%$ & 5 & $45.5 \%$ & 11 & \\
\hline \multicolumn{13}{|l|}{ Use of case-study } \\
\hline Strongly disagree & 0 & $0.0 \%$ & 3 & $100.0 \%$ & $3(100)$ & \multirow{5}{*}{0.015} & 2 & $50.0 \%$ & 2 & $50.0 \%$ & 4 & \multirow{5}{*}{0.998} \\
\hline Disagree & 0 & $0.0 \%$ & 1 & $100.0 \%$ & $1(100)$ & & 1 & $16.7 \%$ & 5 & $83.3 \%$ & 6 & \\
\hline Not sure & 3 & $60.0 \%$ & 2 & $40.0 \%$ & $5(100)$ & & 5 & $71.4 \%$ & 2 & $28.6 \%$ & 7 & \\
\hline agree & 13 & $52.0 \%$ & 12 & $48.0 \%$ & $25(100)$ & & 23 & $39.7 \%$ & 35 & $60.3 \%$ & 58 & \\
\hline Strongly agree & 16 & $33.3 \%$ & 32 & $66.7 \%$ & $48(100)$ & & 23 & $42.6 \%$ & 31 & $57.4 \%$ & 54 & \\
\hline \multicolumn{13}{|l|}{ Use of field trip } \\
\hline Strongly disagree & 4 & $17.4 \%$ & 19 & $82.6 \%$ & $23(100)$ & \multirow{5}{*}{$0.010^{*}$} & 8 & $22.2 \%$ & 28 & $77.8 \%$ & 36 & \multirow{5}{*}{$0.005^{*}$} \\
\hline Disagree & 5 & $45.5 \%$ & 6 & $54.5 \%$ & $11(100)$ & & 10 & $43.5 \%$ & 13 & $56.5 \%$ & 23 & \\
\hline Not sure & 4 & $44.4 \%$ & 5 & $55.6 \%$ & $9(100)$ & & 9 & $45.0 \%$ & 11 & $55.0 \%$ & 20 & \\
\hline agree & 5 & $31.3 \%$ & 11 & $68.8 \%$ & $16(100)$ & & 11 & $52.4 \%$ & 10 & $47.6 \%$ & 21 & \\
\hline Strongly agree & 0 & 0 & 0 & 0 & 0 & & 16 & $55.2 \%$ & 13 & $44.8 \%$ & 29 & \\
\hline
\end{tabular}

This is an SPSS table in bivariate analysis comparing the nurse tutors work experience and students study experience against different teaching strategies for nurse tutors in Malawi. The cut Point of the bivariate analysis was 0.05 power value. The analysis was generated from spearman correlation coefficient in a two-tailed test significance, excluding missing data. 
$61 \%$ of the Nursing tutors who have more than 6 years of work experience strongly agreed that they like using lecture teaching strategy. However, more nurse tutors who have more than 6 years of experience were not sure on the use of lecture method. $63.8 \%$ of the more than two year study experienced students strongly agreed that their nurse tutors had used lecture teaching method in class during last semester. However, using the spearman correlation coefficient in a bivariate analysis, we rejected the null hypothesis that being a two year experienced nursing student is not correlated to the tutors use of lecture method when teaching during last semester as the pvalue was $0.335>p=0.05$. This means that tutors choice of the lecture method does not depend on the student's experience.

Furthermore, $66 \%$ of the nurse tutors who have worked more than 6 years strongly agreed that they had used discussion during classroom and clinical teaching. Only less than $1 \%$ of the nurse tutors strongly disagreed that they had used lecture methods when teaching in Malawi. Even when spearman correction coefficient in a bivariate analysis with a two tailed test of significance, in a no missing data, we rejected the null hypothesis that use of lecture teaching strategy is not correlated to work experience of the tutor. This was done in favour of the alternative hypothesis and dependent variable, use of lecture as a teaching strategy is strongly corrected to nurse tutors work experience as the p-value was $0.009<\mathrm{p}=0.05$. This means that use of lecture teaching strategy is strongly correlated to nurse tutors work experience. Therefore, use of lecture teaching strategy depends upon the nurse tutor work experience

In Table 3, 65.5\% of the nurse tutors who more than 6 years' of work experience have agreed that they had used role play as a teaching strategy during last semester in class. However, only $48.1 \%$ of the students who have more than two years' experience agreed that they their tutors had used role play as a teaching strategy during the last semester. Moreover, there was just a board line correction in the Spearman Correction Coefficient in bivariate analysis using two tailed test of significance as the p-value after comparing use of role play and the nurse tutors work experience was $0.053 \geq \mathrm{p}=0.05$. To expound this discrepancy there was correction when dependent variable use of role play was compared with independent variable nurse tutors work experience as the pvalue was $0.023>p=0.05$.

The result of spearman Correlation Coefficient in the bivariate analysis for nursing students on dependent variable, use of discussion as a teaching strategy, in comparison with independent variable students study experience, showed no correlation because the $\mathrm{p}$-value was $0.396>\mathrm{p}=0.05$. Furthermore, there was a strong correlation between independent variable tutor work experience $(0.033<\mathrm{p}=0.05)$ and dependent variable nurse tutors use of discussion as a teaching strategy in the same bivariate analysis. This still expound the student tutor discrepancy in use of the teaching strategies.

$66.7 \%(32) n=48$ of the nurse tutors who have more than 6 years of work experience agreed that they use case study as a teaching strategy during teaching the students both in class and at the clinical area. But $33.3 \%(16) \mathrm{p}=$ 48 of the nurse tutors who have less than 5 years of work experience also agreed that they use a case study during teaching both in class and at the clinical area. Even when the bivariate analysis was used in a spearman correlation coefficient in a two tailed test of significance we rejected the null hypothesis as the p-value was $0.015<$ $\mathrm{p}=0.05$. This indicates that nurse tutor work experience is strongly correlated to use of case studies during teaching both in class and at the clinical area. So, nurse tutors work experience influences the use of case study as a teaching strategy in nursing in Malawi.

It has also to be pointed out that both students and nurse tutors strongly agreed on the use of field trip (mobile clinic) as a teaching strategy. This is because $68.8 \%$ of more than 6 years of work experienced tutors agreed and $77.8 \%$ of more than two years student study experienced also agreed on the tutor's use of the field trip as a teaching strategy. Even in the bivariate analysis, there was strong correlation in both equations where the p-value from the Spearman Correlation Co-efficient were $0.010>p=0.05$ for nurse tutors and $0.005>p=0.05$ for the nursing students. This means that both students and tutors strongly agree statically that they used field trip as a method of teaching during the last semester. It also entails that use of field trip or clinical trip depends on the tutors work experience and students study experience respectively.

\section{Association of Nurse Tutors' Work Experience, Students' Study Experience and Teaching Strategies}

In order for the study to determine the association of nurse tutors work experience and nursing students study experience in relation to the teaching strategies, a binary logistic regression models were constructed. This was 
done using the Omnibus Tests of Model Coefficient which gave an overall indication of how well the model performed in comparison with nurse tutors experience and teaching strategies. The main aim of this model utilization was to assess the determinants of teaching strategy utilization between nurse tutors and students and the extent to which nurse tutor experience and nursing student study experience affects utilization of the teaching strategies.

In Table 4, the results reveal that there was no association between nurse tutor work experience and the use of lecturer method during teaching by the nurse tutor. This was after the omnibus test of the model coefficient in the binary logistic regression model and the odds ratio was $\mathrm{OR} \leq 0.832 ; \mathrm{CI}(0.522 \pm 1.324) ; \mathrm{p} \geq 0.437$. While the Hosmer and Lemeshow Test was significant with $p=0.437>0.05$. The data further showed that an increase of tutors work experience by one year would likely result to an increase to the use of the lecture as a teaching strategy by 0.369 times. Even the Beta Coefficient value showed a negative direction of the relationship $(\mathrm{B}=$ -0.184 ) between the predictor variable and the dependent variable.

However, there was an association between student study experience and the nurse tutor utilization of the lecture method during teaching in the student data. This was so after comparing the student study experience and the nurse tutors utilization of the lecture teaching strategy. In this model, the probability stepwise criteria of 0.05 were selected for entry point. While the probability stepwise criteria of 0.5 were selected as the classification cut-off point in the equation. The outcome of the logistic regression model was an odds ratio of OR $\leq 1.624$; $\mathrm{CI}(0.576 \pm 4.579) ; \mathrm{p} \geq 0.359$. This clearly illustrates that there is an association between the predictor variable student study experience and the dependent variable nurse tutors utilization of the lecture method during teaching both in class and at the clinical area. For any one year addition to the student study experience there would be a likelihood of 1.624 times more for the nurse tutors to use the lecturer method during teaching. Even the Beta Coefficient value showed a positive direction $(B=0.485)$ of relationship between the predictor variable and the dependent variable.

Table 4. Association of tutors work experience, students study experience and teaching strategies.

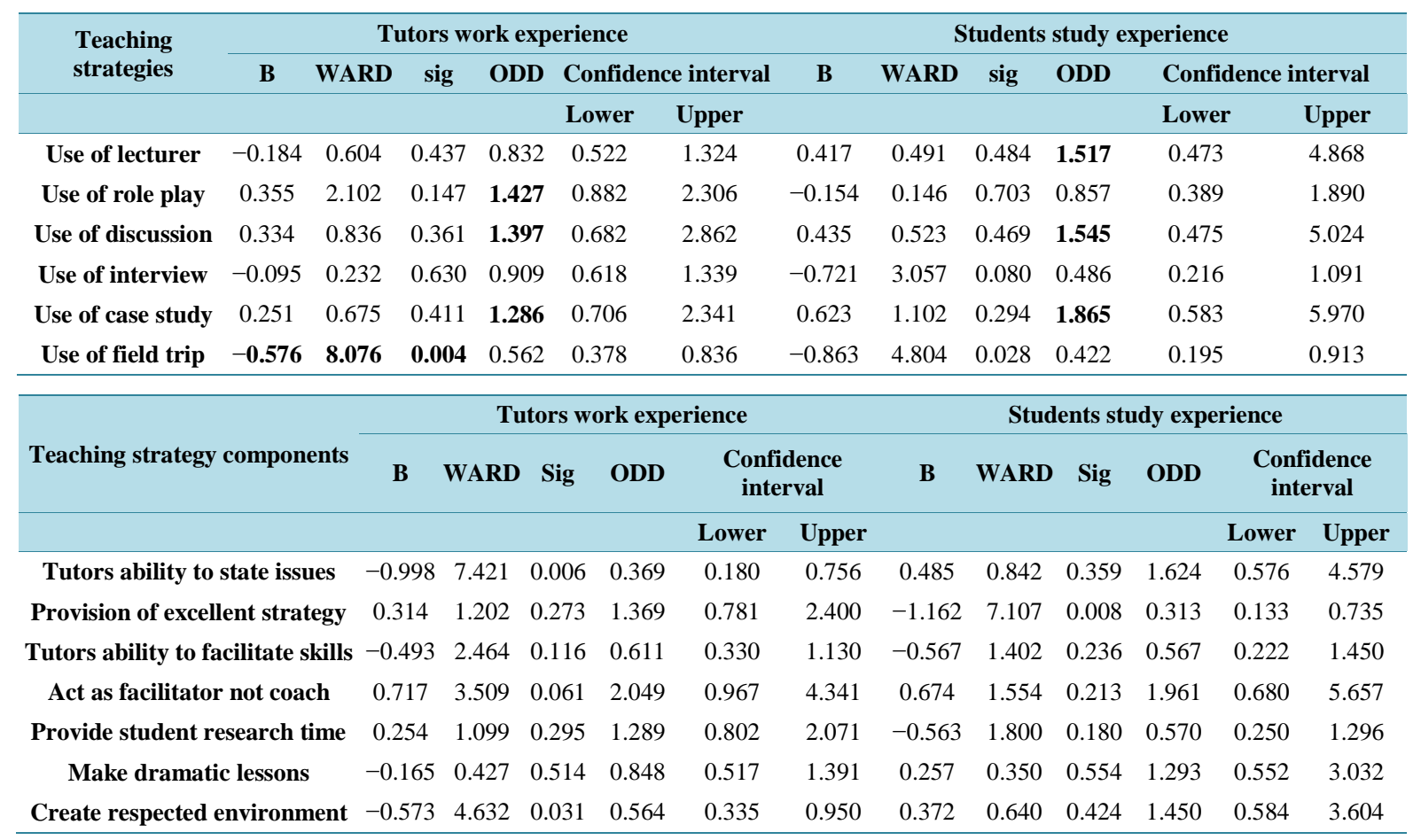

This is a logistic regression models with probability classification cut-off of 0.5 and the entry point of p-value of 0.05 in statistics of Hosmer-Lemeshow goodness of-fit. Basing on method of ENTER, the maximum iteration of 20, the equation had a probability of $95 \%$ confidence interval. The OR interpretation of above 1 was adopted for the predictor variables of nurse tutor experience and student study experience separately. All the categorical dependent variables and the predictor/independent variables were first tested in the bivariate analysis at p-value of 0.05 . All constant values are not tabulated although the models produced. The degree of freedom was set at 1 ; all teaching strategy dependent and nurse tutor work experience and student study experience which are independent categorical variables were dichotomizedly coded correctly (with $0=$ disagree or lack of the characteristic(); 1 = agree, or the presence of the characteristic. 
This means that for any increase in years of student study experience there would be also an increase in the nurse tutor utilization of the lecture method during teaching. Therefore, in Malawi nursing colleges although the nurse tutors refuse to be mostly using the lecture method during teaching but student often observe that nurse tutors use lecture method during teaching particularly in class.

Use of role play during teaching has also been found to be highly associated with the nurse tutor work experience in this study. This was done in the binary logistic regression analysis where omnibus test of model coefficient was the main choice. The outcome of the model equation was confidence interval, p-value and the odds ratio as follows: $\mathrm{OR} \leq 1.624 ; \mathrm{CI}(0.576 \pm 4.579) ; \mathrm{p} \geq 0.359$. This entails that if there is a one year addition to the nurse tutor work experience there would be a likelihood chance of 1.369 times for nurse tutors to utilise the role play during teaching. Hence this indicates that for nurse tutors the likelihood of utilising the role play as a teaching strategy is influenced by the years of work experience. Therefore, it has to be noted that the more the nurse tutors' work experience the more chances she or he has to use role play as a teaching strategy during the last semester both in class and at the clinical area in Malawi nursing colleges. Even in the Beta Coefficient as shown on Table 4, there was a positive direction of the relationship $(B=0.355)$ between the nurse tutor work experience and the nurse tutors utilization of the role play although it was in decimal point. This also signifies that any increase to nurse tutor work experience in years there would also be a likelihood increase to the nurse tutor utilization of the role play as the teaching strategy during teaching.

However, in the student data, when student study experience was compared to nurse tutor utilization of the role play as the teaching strategy, in the binary logistic regression analysis, there was no association. The outcome results of the binary logistic regression was an odds ratio of $\mathrm{OR} \leq 0.857$; $\mathrm{CI}(0.389 \pm 1.890)$; $\mathrm{p} \geq 0.703$. It also explains that if one year is added in constant to the student study experience there would be a likelihood chance of 0.857 times of the nurse tutors to use the role play as a teaching strategy during teaching in class in their nursing colleges in Malawi. This shows that use of role play by nurse tutors is not influenced by the student study experience. Even the Beta Coefficient value from the equation of the binary logistic regression, showed a negative direction of the relationship $(B=-0.154)$ between the predictor variable student study experience and the dependent variable nurse tutors utilization of the role play during teaching in class. Therefore, it openly shows that if there is an increase in the years of student study, there would be a decrease in the nurse tutor role play utilization as the teaching strategy in class in Malawi nursing colleges.

The results has also shown that nurse tutors work experience increases the chances of utilising the discussion teaching strategy as the Odds Ratio was $\mathrm{OR} \leq 1.397$; $\mathrm{CI}(0.882 \pm 2.306) ; \mathrm{p} \geq 0.147$. This was found after using the logistic regression model where an omnibus test of model correlation coefficient was chosen. The main aim was to compare the independent variable nurse tutor work experience and the use of discussion method by the nurse tutor. The results then suggest that with more nurse tutor work experience by one year there would be a likelihood chance of using discussion method by 1.397 times. However, student data were also used to compare predictor variable student study experience and dependent variable the nurse tutors utilization of the discussion teaching strategy during teaching. in the binary logistic regression model, probability stepwise criteria of 0.05 was used for entry point and 0.1 was used for removal point where the classification cut-off point was set to be 0.5. In this logistic regression model, the omnibus test of model coefficient was adopted and there was no missing data. It has also to be pointed out that the more student study experience the more likelihood of utilising the discussion method during learning, as the student data Odds Ratio was $\mathrm{OR} \leq 1.545 ; \mathrm{CI}(0.475 \pm 5.024) ; \mathrm{p} \geq$ 0.469. This is because if there is a constant addition of one year to the nurse tutor work experience there would be 1.545 times of the nurse tutors utilizing the discussion method during teaching both in class and at the clinical area. This means that the more student study experienced are, the more likelihood chances they would utilise the discussion as a teaching strategy in the last semester.

Use of case study has also been found to have an increased chances of being utilized by nurse tutors due to work experience as the Odds Ratios were $\mathrm{OR} \leq 1.286$; $\mathrm{CI}(0.706 \pm 2.341) ; \mathrm{p} \geq 0.411$. This was found after a binary logistic regression model where an omnibus test of model coefficient was used. In the model the probability stepwise of 0.5 was used as the classification cut-off point. In this case study it clearly indicates that there is an association between predictor variable, nurse tutor work experience and the dependent variable use of case study during teaching both in class and at the clinical area. This means that the likelihood of nurse tutors to use a case study as a teaching strategy during teaching in last semester was 1.286 times more and depended on their number of years work experience. Even the Beta Coefficient was found to have a positive direction of the relationship ( $\mathrm{B}=0.251$ ) between nurse tutor work experience and the nurse tutors utilization of the case study dur- 
ing teaching both in class and at the clinical area. This applies the same to students whose utilization of the case study during learning depended on their number of years of study experience $\mathrm{OR} \leq 1.865$; $\mathrm{CI}(0.583 \pm 5.970)$; $\mathrm{p} \geq$ 0.294 . This means that any addition on one year as a constant value to the student study experience, would lead to a likelihood chance of 1.865 times for the nurse tutors to utilize the case study as a teaching strategy during teaching both in class and at the clinical area. In this result, it indicated that the more experienced the student become after achieving higher class the more chances the nurse tutor has of utilising the case study as a teaching strategy. Moreover, the Beta Coefficient results too in this equation $(B=0.623)$ produced the positive direction of the relationship (although in decimal points) between the student study experience and the nurse tutors utilisation of the case study as a teaching strategy during teaching both in class and at the clinical area. So, any increase to the student study experience would lead to the increase too to the nurse tutor utilisation o the Furthermore, the binary logistic regression model was used to compare the nurse tutor work experience and the utilisation of the field trip or clinical trip as a teaching strategy during teaching by the nurse tutor. In this model, there was no association of the predictor variable nurse tutor work experience and the dependent variable utilisation of the field trip during teaching by the nurse tutors. This was because the outcome of the odds ratio was OR $\leq$ 0.562 ; $\mathrm{CI}(0.378 \pm 0.836) ; \mathrm{p} \geq 0.004$. So, it illustrates that for any addition in constant of one years to the nurse tutor work experience there would be a likelihood chance of 0.562 times for the nurse tutors to utilised the field trip or clinical trip as a teaching strategy during teaching both in class and at the clinical area. Therefore, Clinical trips or field trip was also found to be negatively affected by both the nurse tutors work experience and student study experience as the Beta Coefficient was -0.576 . This means that the direction of the relationship between nurse tutors work experience and the use of clinical trips was not positive. This implies that the more the years of nurse tutors work experience the less likely the use of the clinical trip as a teaching strategy. Furthermore, in the student data, it was also found that there is no association of the student study experience and the nurse tutors utilization of the field trip as the teaching strategy during teaching both in class and at the clinical area. This was after a binary logistic regression model where 0.05 was used as the entry point and 0.5 was set as the classification cut-off point in the equation. The results expresses the odds ratio of $\mathrm{OR} \leq 0.422$; $\mathrm{CI}(0.195 \pm$ 0.913); $\mathrm{p} \geq 0.028$. The results indicates that if there is an addition of the constant one year to the student study experience there would be a likelihood chance of 0.422 times for the nurse tutor to use field trip during teaching both in class and at the clinical area. Therefore, student study experience does not influence field trip as a teaching strategy. This trend also affected the students as it was found out that the Beta Coefficient was -0.863 . This means that the more the number of student study years is, the less likely the use of clinical trip as a teaching strategy is.

The results in Table 4 also show that nurse tutors' ability to state issues clearly decreases with each more year of nurse tutor work experience as the Beta. Value from the binary logistic regression analysis was -0.998 . This illustrates that any increase in the nurse tutors work experience in years would lead to a decrease in the nurse tutors ability to state issues clearly during teaching to student both in class and at the clinical area. Even using Hosmer and Lemeshow Test in the binary logistic regression there was no association between independent variable nurse tutor work experience and tutors' ability to state issues in class or at the clinical area as the odds ratio from the binary logistic regression equation was $\mathrm{OR} \leq 0.369$; $\mathrm{CI}(0.180 \pm 0.756) ; \mathrm{p} \geq 0.006$. This indicates that for any one year addition to the nurse tutor work experience as a constant value, would lead to a less likelihood chance of 0.369 times for the nurse tutor to have ability to state issues necessary for student teaching both in class and the clinical area. Moreover, even in the Beta coefficient $(B=-0.998)$ there was a negative direction of the relationship between nurse tutors work experience and the nurse tutors ability to state issues clearly during teaching students both in class and at the clinical area. But student data had different results as the odds ratio from the binary logistic regression model was $\mathrm{OR} \leq 1.624$; $\mathrm{CI}(0.576 \pm 4.579) ; \mathrm{p} \geq 0.359$. This results shows that there is an association between the student study experience and the nurse tutors ability to state issues to students during teaching both in class and at the clinical area. for one year extra as a constant value in the student study experience would likely lead to 1.624 times for the nurse tutors to have the ability to state issues to students during teaching both in class and at the clinical area. Even the Beta Coefficient was showing the positive direction of relationship $(\mathrm{B}=0.485$ ) between student study experience and the ability of the nurse tutors to state issues during teaching both in class and at the clinical area.

Nurse tutors ability to act as a facilitator for student skills in class during teaching was also evaluated using the binary logistic regression model. This was done to compare the nurse tutors work experience and the nurse tutors ability to act as a facilitator in student skills during teaching. The model adopted the probability stepwise 
criteria of 0.05 as the entry point and 0.1 as the removal point with a classification cut-off point of 0.5 . The result of the omnibus test of model coefficient which were in confidence interval, p-value and the odds ratio was $\mathrm{OR} \leq 0.611$; $\mathrm{CI}(0.330 \pm 1.130) ; \mathrm{p} \geq 0.116$. This means that there is no association between the predictor variable nurse tutor work experience and the dependent variable nurse tutors ability to facilitate student skills during teaching both in class and at the clinical area. If an addition of one year as a constant value is added to nurse tutor work experience there would be 0.611 times for the nurse tutors to have a less likelihood ability to act as the facilitators for student skills in class during teaching. This was also evidenced through the Beta Coefficient from the equation of the binary logistic regression analysis $(B=0.314)$ the result showed that there was a positive direction of the relationship between the nurse tutors work experience and the nurse tutors ability to act as the facilitators in student skills during teaching. However, this was not the same in the student data, as there was no association between student study experience and the nurse tutors ability in acting as facilitators during teaching. This was after the same logistic regression analysis where the omnibus test of model coefficient was selected. In the model the classification cut-off point was 0.5 with 0.05 was the probability stepwise criteria as the entry point. Therefore, after comparing the predictor variable student study experience and the nurse tutors ability to act as facilitator, the result of the binary logistic regression equation was $\mathrm{OR} \leq 0.567 ; \mathrm{CI}(0.222 \pm 1.450) ; \mathrm{p} \geq$ 0.236 . The result illustrates that if there is a constant increase of one year to the student study experience there would be a less likelihood chance of 0.567 time for the nurse tutors to have the ability to act as a facilitator on student skills during teaching. Moreover, the Beta coefficient from the binary logistic regression equation showed the negative direction of the relationship $(\mathrm{B}=-0.567)$ between the student study experience and nurse tutors action as the facilitators on student skill during teaching. This entails that any increase in the student study experience in years there would be a likely decrease in the nurse tutors ability to act as a facilitator in the student skills during teaching both in class and at the clinical area.

The teaching strategy of the nurse tutor was also evaluated on the facilitation rather than coaching the students .Therefore, when the omnibus test of the model coefficient was used on predictor variable of nurse tutor work experience and dependent variable of acting as a facilitator not coach, the Odds Ratio was OR $\leq 2.049$; $\mathrm{CI}(0.967 \pm 4.341) ; \mathrm{p} \geq 0.061$. This suggests that the more work experienced the nurse tutor is the more likely he or she would act as a facilitator not coach during teaching in the last semester. This was also echoed by the students who also agreed that their nurse tutors indeed act as a facilitator not coach. This was based on the results of the binary logistic regression where independent variable student study experience was associated with dependent variable acting as a facilitator not coach as the Odds Ratio was $\mathrm{OR} \leq 1.961$; $\mathrm{CI}(0.680 \pm 5.657)$; $\mathrm{p} \geq$ 0.213. This entails that if one year is added to the student study experience there would be a more likelihood chance of 1.961 times for the nurse tutors to act as facilitators not coaches during teaching the students both in class and at the clinical area. It is also worth noting that the direction of Beta Coefficient results in the omnibus test of the model coefficient was negative for the predictor variable of nurse tutor work experience and the dependent variable tutors ability to facilitate clinical skills $(\mathrm{B}=-0.493$ for Tutors and $\mathrm{B}=-0.567$ for students). This is very crucial in terms of clinical nursing as it suggests that the more years nurse tutor has on work experience the less likely that she or he has an ability to facilitate classroom and clinical skills at the in the nursing college.

The use of the teaching strategy by nurse tutors was also evaluated on how they make dramatic lessons for students to be interested during teaching. Using binary logistic regression analysis, the predictor variable nurse tutor work experience was compared to dependent variable nurse tutor making of the dramatic lessons for students to be interested during teaching. This was after adopting the probability stepwise criteria of 0.05 as the entry point, and 0.1 as the removal point and a classification cut-off point of 0.5 . The main binary logistic regression results that included the odds ratio was $\mathrm{OR} \leq 0.848$; $\mathrm{CI}(0.517 \pm 1.391) ; \mathrm{p} \geq 0.514$. This means that there is no association between nurse tutor work experience and making of the dramatic lesson during teaching for the nurse tutors. Moreover, the Beta coefficient of the equation also showed a negative direction of the relationship ( $B=-0.165)$ between nurse tutor work experience and the nurse tutors making of the dramatic lesson for student to be interested in their courses during teaching both in class and at the clinical area. The result illustrates that any increase to the nurse tutor work experience in years would result to a decrease in the nurse tutors making of dramatic lesson for students to be interested during teaching. Therefore, in Malawi nursing colleges it has been found out that nurse tutors do not make dramatic lessons for students to be interested during teaching both in class and at the clinical area.

Nurse tutors were also evaluated on whether they create respected environment for students during teaching 
both in class and at the clinical area. This was done by comparing the predictor variable nurse tutor work experience and the dependent variable nurse tutors creation of respected environment to students during teaching both in class and at the clinical area. The odds ratio results in the equation showed that there was no association between nurse tutor work experience and the creation of the respected environment during teaching by the nurse tutor to students. This is because the results were $\mathrm{OR} \leq 0.564$; $\mathrm{CI}(0.335 \pm 0.950) ; \mathrm{p} \geq 0.031$. This illustrates that if there is an addition of one years as a constant value to the nurse tutor work experience there would be a less likelihood chance of 0.564 time for the nurse tutors to create respected environment to students during teaching. Although the Odds Ratio for students logistic regression showed $\mathrm{OR} \leq 1.450$; $\operatorname{CI}(0.584 \pm 3.604) ; \mathrm{p} \geq 0.424$ which means more student study experience was most likely to affect the nurse tutors creation of more respect environment during learning. But the nurse tutors work experience showed that there would less likely affect the creating of respectful environment in the Beta coefficient value (Beta $=-0.573$ ) during teaching and learning both in class and at the clinical area. This indicates that what the tutors are perceiving on the respectful teaching environment would not necessarily what the students are perceiving.

\section{Discussion}

This study has found out that direct nursing instructions which are more teacher-centered are the commonest teaching strategies that are used by nurse tutors in Malawi. Lecture teaching strategy still remains as the most common among the direct teaching strategies. But most of the nurse tutors combine the strategy with others like question and answers. The combination helps them to employ interactive nature between the students and the nurse tutor. If the presenter of lecture teaching strategy is knowledgeable, perceptive, engaging, and motivating, then lecture can stimulate reflection, challenge the imagination, and develop curiosity and a sense of inquiry [10]. Criteria for the selection of the lecture method included the types of experiences nurse tutors and students afforded and the kinds of learning outcomes that was expected. Because lecture is teacher-centred and student activity is mainly passive, the attention span of students is improved with the combination with other teaching strategies. However, in Malawi nursing colleges since the learners are adults it is very important for nurse tutor to be cautious on the utilization of the lecture method as the adult students would be sensitive to the learning process. This study has cemented what literature has pointed out that in USA [13], as Nearly $80 \%$ of all U.S. college classrooms in the late 1970s reported using some form of the lecture method to teach students [14]. Although the usefulness of other teaching strategies is being widely examined today, the lecture still remains an important way to communicate information in USA [15]. Furthermore, lecture teaching strategy is used in conjunction with active learning teaching strategies, the traditional lecture can be an effective way to achieve instructional goal if it is combined with other teaching instructions. It is very interesting that this study has found out that there is no association between nurse tutor work experience and the utilization of the lecture teaching strategy. This means that number of years that the nurse tutor work does not influence the utilization of the lecture method.

Although Role play has 54\% on utilization among the nurse tutors but it is one of the best interactive teaching instruction that has been recommended in most studies in nursing. This approach has the potential to enhance the capacity of at-risk students to process complex information, to nurture their development as critical thinkers, and to improve nursing student overall academic performance. Role play increases student knowledge acquisition particularly in the classroom situation [16]. This interactive teaching strategy enhances nursing students' motivation to learning. It is very important to create student motivation at an early stage in the learning process in nursing education so that when the students have started clinical practice, they can perform at high standard level. It is therefore very encouraging that the analysis of this role play teaching strategy utilization has been found to have high statistical significance with nurse tutor work experience. The more years that nurse tutor use this strategy the more accurate the utilization. However, combination with other teaching strategies has shown that it helps to uplift the quality of the presentations or delivery of the nursing education in both the classroom situation and the clinical area.

It is also very encouraging that nurse tutors in Malawi use mostly discussion method as it is an interactive teaching strategy that promotes student-tutor relationship. Both the nursing students and the nurse tutors in Malawi agreed that the use of discussion teaching strategy is very influential in their teaching and learning processes. Understanding of medical conditions and diseases needs more active learning process. Without active learning process, the acquisition of most of the medical jargon can be limited. Medical education requires student collective group discussions which enhances self-awareness and reflection [17]. Therefore, the nurse tutor 
experience helps to influence the qualitative utilization of the group discussion. However, combination of the group discussion with other teaching strategy like question and answer has also been proved to be under best evidence medical education (BEME). Even current literature pointed out the use of combined teaching strategies promoted portfolio utilization in UK [18].

Nurse tutors in Malawi have shown that they use case study teaching strategy very often. There has been also a binary logistic regression statistical association in both the nurse tutor work experience and the student experience. This is a true reflection of the case study utilization that it depends on the nurse tutors work experience and the students study experience. It is not expected that a novice student to indulge into this teaching strategy but those students that have more student learning periods in nursing do use the strategy. Case study teaching strategy has an influence in student learning on emergency medicine for third year students [19]. This is in line with what has been found in this study that experienced nurse tutors involved the second year and third year students in Malawi nursing colleges to indulge into case study teaching strategies in the clinical area.

The utilization of the field trip as a teaching strategy has been found to be very weak in Malawi nursing colleges. It has to be mentioned that field trip is called community field work in nursing education in Malawi. Nurse tutors and students do not go to the community so often unless it is time for community course that appear commonly in second year. Therefore, although there has been no statistical association of the Odds ratio in the regression model but there was a strong statistical p-value of $0.004<$ p. 0.05 . This was a true reflection of the significance of the field trip teaching strategy in nursing education in Malawi nursing colleges. Nurse tutors use this method when they want their nursing students to learn community oriented health conditions like industrial hygiene and community sanitation or school health.

The ability of the nurse tutors to use the teaching strategies effectively in class has been found to be very limited. This is not only due to limited resources but also due to level of knowledge among the nurse tutors. Teaching strategy is delivered efficiently when the resources are available. Nurse tutors in Malawi struggle as they are very few [9]. This is complicated with limited funding of the colleges where teaching resources are always very limited. For example, at Nkhoma nursing College there were only two working LCD projectors against three classes of first year, second year and third nursing students. Yet classes are surpassed to be conducted 8 hours a day. This affected some nurse tutors who could go to class to teach using teaching strategies like lecture by wring on the chalkboard. In such condition nurse tutors facilitation to the teaching process is limited. Whatever teaching and learning style that is adopted one has to remember that students attend courses with their individual presage variables. These variables provide some insight on the subtle differences that illustrate the uniqueness of each adult learner [20]. These variables include; motivation, expectations, knowledge retention in relation to short and long term memory, knowledge, skills, competencies and experience, powers of concentration, problem solving ability, access to student support facilities, study time available, learning capacity and orientation to learning [21]

\section{Conclusion}

Direct teaching strategies have been found to be so commonly used by nurse tutors in Malawi nursing colleges. If the lecture teaching strategy is combined with other teaching strategies, the outcome yields effective learning in nursing students in Malawi. Therefore, it needs to develop a teaching strategy that can have different attributes from the varieties of the teaching instructions if classroom and clinical nursing is to be improved in Malawi.

\section{References}

[1] Perry, B. and Edwards, M. (2005) Exemplary Online Educators: Creating a Community of Inquiry. 4th Edition, Springer Publishing Company, New York.

[2] Caffrey, M. and Graeme, F. (2006) Health Workforce "Innovative Approaches and Promising Practices” Study: Attracting and Retaining Nurse Tutors in Malawi; Capacity. Project USAID Global Health/HIV/AIDS and the Africa Bureau Office of Sustainable; Development, Lilongwe.

[3] Waterson, E., Harms, E., Qupe, L., Maritz, J., Manning, M., Makobe, K. and Chabeli, M. (2006) A Curriculum Overload; Lack of Theory and Practice. Curationis, 29, 56-65.

[4] Posey, L. and Pintz, C. (2006) Online Teaching Strategies to Improve Collaboration among Nursing. Students Nurse Education Today, 26, 680-687. http://dx.doi.org/10.1016/j.nedt.2006.07.015 
[5] WHO, World Health Organization (2007) Indicators of Health in Malawi. Annual Report, Geneva.

[6] Nurses Council of Malawi (NCM) (2007) Progress of Nurses in Development. Annual Report, Lilongwe.

[7] Hoke, M.M. and Leslie, K.R. (2005) The Impact of Active Learning on Nursing Students' Clinical Success. Journal of Holistic Nursing, 23, 348-355. http://dx.doi.org/10.1177/0898010105277648

[8] Chirwa, M. (2007) Performance of Cham Nursing Schools, Lilongwe.

[9] Grigulis, A.L. (2010) Lives of Malawian Nurses: Stories behind the Startistics. PhD Thesis, Centre for International Health and Development, University College London, London.

[10] Saskatoon Public Schools (2013) French Immersion. Saskatoon Public Schools, Saskatoon.

[11] Cox, M., Irby, D.M. and Bowen, J.L. (2011) Educational Strategies to Promote Clinical Diagnostic Reasoning. New England Journal of Medicine, 355, 2217-2225. http://dx.doi.org/10.1056/NEJMra054782

[12] Maunye, T.J., Meyer, S.M. and van Velden, C.E. (2009) An Assessment of Teaching Strategies Used by Lecturers at a Nursing College in Mpumalanga. Curationis, 32, 30-37.

[13] Gaberson, K. and Oermann, M.H. (2009) Clinical Teaching Strategies in Nursing. 4th Edition, Springer Publishing Company, New York.

[14] Cashin, W.E. (2010) Student Ratings of Teaching: Recommendations for Use. IDEA Paper No. 22, Center for Faculty Evaluation and Development, Kansas State University, Manhattan.

[15] Johnson, M. (2009) Evaluation of Learning Style for First Year Medical Students. International Journal for the Scholarship of Teaching \& Learning, 3. http://www.georgiasouthern.edu/ijsotl

[16] Miller, A. (2001) Reaching across the Divide: The Challenges of Using the Internet to Bridge Disparities in Access to Information. First Monday, 6. http://firstmonday.org/issues/issue6_10/miller/index.html

[17] Masoomi, R. (2012) What Is the Best Evidence Medical Education? Research and Development in Medical Education, 1, 3-5.

[18] Buckley, S., Coleman, J. and Khan, K. (2010) Best Evidence on the Educational Effects of Undergraduate Portfolios. Blackwell Publishing Ltd., The Clinical Teacher, 7, 187-191.

[19] Khandelwal, S., Bernard, A.W., Wald, D.A., Manthey, D.E., Fisher, J., Ankel, F., Williams, S.R., et al. (2012) Developing and Assessing Initiatives Designed to Improve Clinical Teaching Performance. Academic Emergency Medicine, 19, 1350-1353. www.aemj.org

[20] Banning, M. (2005) Approaches to Teaching: Current Opinions and Related Research. Nurse Education Today, 25, 502-508.

[21] Ministry of Health-MOH (2012) Annual Report on Nurse’s Performance. Capitol Hill, Lilongwe. 